Article

\title{
Enhanced Thermoelectric Performance of Indacenodithiophene-Benzothiadiazole Copolymer Containing Polar Side Chains and Single Wall Carbon Nanotubes Composites
}

\author{
Zhongming Chen ${ }^{1, *}$, Tongchao Liu ${ }^{1,2}$, Chengjun Pan ${ }^{2}$ and Guiping Tan ${ }^{1, *}$ \\ 1 School of Environment and Civil Engineering, Dongguan Cleaner Production Technology Center, Dongguan \\ University of Technology, Dongguan 523808, China; liu21645@163.com \\ 2 Shenzhen Key Laboratory of Polymer Science and Technology, College of Materials Science and Engineering, \\ Shenzhen University, Shenzhen 518060, China; pancj@szu.edu.cn \\ * Correspondence: zmchen@dgut.edu.cn (Z.C.); tangp@dgut.edu.cn (G.T.)
}

Received: 18 March 2020; Accepted: 4 April 2020; Published: 7 April 2020

\begin{abstract}
Composite films of indacenodithiophene-bezothiadazole copolymers bearing polar side chains (P1) and single wall carbon nanotubes (SWCNTs) are found to show a competitive thermoelectric performance compared to their analogous polymers with aliphatic side chains (P2). The enhanced power factors could be attributed to the stronger interfacial interactions between the P1/SWCNTs compared to that of $\mathbf{P 2} / \mathrm{SWCNTs}$ containing the same ratio of SWCNTs. A maximum power factor of $161.34 \mu \mathrm{W} \mathrm{m}{ }^{-1} \mathrm{~K}^{-2}$ was obtained for the composite films of P1/SWCNTs for a filler content of 50 $w t \%$, which is higher than that of P2/SWCNTs ( $\left.139.06 \mu \mathrm{W} \mathrm{m}^{-1} \mathrm{~K}^{-2}, 50 \mathrm{wt} \%\right)$. Our work sheds light on the design of side-chains in efficient conjugated polymers/SWCNTs thermoelectric materials and contributes to the understanding of their thermoelectric properties.
\end{abstract}

Keywords: organic thermoelectric materials; interfacial interactions; composites

\section{Introduction}

In the development of next-generation green energy materials, great attention has been paid to organic thermoelectric materials (OTEs) which can directly convert thermal energy into electricity [1-7]. Conjugated polymers (CPs) are an intriguing class of semiconductors widely used in the field of organic electronics (such as organic light-emitting diodes (OLED), organic field-effect transistors (OFETs), sensors, etc.) [8-12] due to their low toxicity, low thermal conductivity and mechanical flexibility. Recent results have shown that CPs are among the most promising materials for application in flexible thermoelectric generators [13-17]. For example, poly(3,4-ethylenedioxy- thiophene) (PEDOT) with a high thermoelectric figure of merit (ZT) of 0.45 has been reported [18], which stimulated the investigation of $\mathrm{CPs}$ to be used for thermoelectric generators.

In order to achieve high performance thermoelectric materials, both large a Seebeck coefficient (S) and high electrical conductivity $(\sigma)$ are necessary according to the following equation [19]:

$$
Z T=S^{2} \sigma \mathrm{T} / \kappa
$$

Organic materials generally possess large Seebeck coefficients (S) and low thermal conductivity [13-19], therefore, the main challenge of achieving high-performance OTEs is how to improve the electrical conductivity of CPs without sacrificing their large Seebeck coefficients and low thermal conductivity [20,21]. Many strategies have been attempted to improve the conductivities 
of CPs (such as structural manipulations [22], strengthening the ordering of polymer packing [23], efficient doping [24], and forming composites with highly conductive inorganic materials [25], etc.).

$\mathrm{CPs} /$ inorganic thermoelectric composites are one of the major types of organic thermoelectric materials which combine the large Seebeck coefficient feature of CPs with the low thermal conductivity and high electrical conductivities of inorganic nanomaterials [26-33]. Single wall carbon nanotubes (SWCNTs) are one type of attractive carbon nanomaterial for forming thermoelectric composites, attributed to their high electric conductivity and excellent flexibility [27]. Therefore, various kinds of CPs/SWCNTs composites have been prepared and their thermoelectric properties were investigated [26-33]. It was found that the interfacial interactions between SWCNTs and CPs are crucial to enhance the charge carrier mobility for the composites. Thus a few attempts to fine tune the interfacial interactions of the composites and improve their thermoelectric performance through enhancing the charge carrier mobility have been reported [34-36].

The introduction of polar side-chains into CPs has been considered an efficient method to increase the interfacial interactions between CPs and SWCNTs, thus improving the thermoelectric performance. For example, Bazan et al. found that conjugated polyelectrolytes (CPEs) with pendant ionic functionalities can serve as good dispersants and efficient dopants of SWCNTs, allowing a series of p-type or n-type solution-processable composites to be prepared [37]. Crispin et al. demonstrated that optimally p-doped poly(3-hexylthiophene) (P3HT)/CNT composite films could raise the thermoelectric properties to a competitive level (maximum power factor: $95 \pm 12 \mu \mathrm{W} \mathrm{m}{ }^{-1} \mathrm{~K}^{-2}$ ) [38].

Herein, we report the synthesis of two indacenodithiophene (IDT)-benzothiadiazole-based copolymers bearing polar side chains (P1) and aliphatic side chains (P2), respectively. Polymer/ SWCNTs composites with different amounts of SWCNTs have been prepared. The effect of the polar side chain on the properties of the intrinsic polymers as well as the composites have been thoroughly investigated. We found that the polar polymer side chains have no effect on the photophysical and electronic features of the polymer backbone, however, their interfacial interactions are stronger than those of polymers with aliphatic side chains. The enhanced interfacial interactions of P1/SWCNTs provide the composites with a power factor of $161.34 \mu \mathrm{W} \mathrm{m} \mathrm{m}^{-1} \mathrm{~K}^{-2}(50 \mathrm{wt} \%)$, larger than that of P2/SWCNTs $\left(139.06 \mu \mathrm{W} \mathrm{m}{ }^{-1} \mathrm{~K}^{-2}\right)$ for the same compositing ratio.

\section{Materials and Methods}

\subsection{General Conditions}

${ }^{1} \mathrm{H}-\mathrm{NMR}$ spectra of the polymers were acquired on an AVANCE III $600 \mathrm{MHz}$ NMR spectrometer (Bruker, Fällanden, Switzerland) at room temperature in $\mathrm{CDCl}_{3}$. Chemical shifts are expressed in parts per million (ppm, $\delta$ scale) and are referenced to tetramethylsilane (TMS). Thermal gravimetric analysis (TGA) was performed on a TGA-55 instrument (TA Instruments, NewCastle, DE, USA) from room temperature to $700{ }^{\circ} \mathrm{C}$ under a $20 \mathrm{~mL} \mathrm{~min}^{-1}$ nitrogen flow and a heating rate of $10{ }^{\circ} \mathrm{C} \mathrm{min}-1$. The molecular weights and polydispersity index (PDI) of the polymers were determined by gel permeation chromatography (GPC) (Waters e2695 Separations Module, Waters, Singapore) using THF as the eluent in the room temperature, and polystyrene was used as a standard. Differential scanning calorimetry (DSC) was performed on a DSC7020 instrument (DSC7020, Tokyo, Japan), in which three polymers were measured in a temperature range from $0{ }^{\circ} \mathrm{C}$ to $300{ }^{\circ} \mathrm{C}$ at a heating rate of $10{ }^{\circ} \mathrm{C} \mathrm{min}-1$, opened pans without caps were used in the DSC experiments. Ultraviolet-visible-near-infrared (UV-vis-NIR) absorption spectra were acquired using a Lambda 950 spectrophotometer (PerkinElmer, Waltham, MA, USA), using thin films samples casted on quartz plates. The morphology of the polymer films was observed by a SU-70 scanning electron microscope (SEM) (Hitachi SU-70, Tokyo, Japan), and the thickness of the films was obtained on a Surfcorder ET 4000M (Kosaka Laboratory, Tokyo, Japan). The Raman spectra were recorded on a Renishaw in Via-Reflex Raman microscope (Renishaw inVia ${ }^{\mathrm{TM}}$ Raman Microscope, London, England). Cyclic voltammetry (CV) was performed on a CHI 660E electrochemical workstation (Chenhua Instruments Co., Shanghai, China). A platinum plate, $\mathrm{Ag} / \mathrm{AgCl}$ 
and a platinum wire were used as the working, reference and counter electrodes, respectively, in $0.1 \mathrm{M}$ tetrabutylammonium hexafluorophosphate $\left(\mathrm{Bu}_{4} \mathrm{NPF}_{6}\right) /$ acetonitrile under a nitrogen atmosphere at a scan rate of $50 \mathrm{mV} \mathrm{s}^{-1}$. The reference electrode was calibrated with ferrocene/ferrocenium $\left(\mathrm{Fc} / \mathrm{Fc}^{+}\right)$. Grazing incidence X-ray diffraction (GI-XRD) was measured on a SmartLab X-ray diffractometer (Rigaku, Tokyo, Japan) with a copper target $\left(\lambda=1.54 \AA\right.$ ), and the incident range was $2-40^{\circ}$, the thin films samples are casted on the quartz plates. The electrical conductivity $(\sigma)$ and Seebeck coefficient (S) of the polymer films were collected using an MRS-3 thin-film thermoelectric test system (Wuhan Joule Yacht Science \& Technology, Wuhan, China). The thin films samples are casted on quartz plates, and the measurements are carried out under vacuum at room temperature.

\subsection{Syntheses of the Monomers and Copolymers}

\subsubsection{Synthesis of the Monomer M1}

M1 was synthesized using a previously reported method [39]. A mixture of di(ethylene glycol) ethyl ether $(0.300 \mathrm{~g}, 2.23 \mathrm{mmol})$ and THF $(6 \mathrm{~mL})$ was added to a $50 \mathrm{~mL}$ two-necked flask. The flask was evacuated and refilled with nitrogen several times, then sodium hydride $(\mathrm{NaH})$ powder was added slowly at $0{ }^{\circ} \mathrm{C}$, and the reaction mixture was stirred for $3 \mathrm{~h}$. 4,7-Dibromo-5,6-difluoro-2,1,3-benzothiadiazole $(0.409 \mathrm{~g}$, $1.24 \mathrm{mmol})$ dissolved in anhydrous THF $(10 \mathrm{~mL})$ was then added via syringe, and the reaction mixture was gradually warmed to room temperature. After stirring for $15 \mathrm{~h}$, the reaction mixture was diluted with dichloromethane (DCM) and washed sequentially with water ( 3 times) and brine. The organic layer was dried over magnesium sulphate $\left(\mathrm{MgSO}_{4}\right)$ and concentrated under reduced pressure. The crude product was purified through silica gel column chromatography (DCM/hexane: $3 / 4$ ), to afford a white powder (yield: $50 \%$ ). ${ }^{1} \mathrm{H}-\mathrm{NMR}$ $\delta(\mathrm{ppm}): 1.16\left(\mathrm{dd}, 6 \mathrm{H}, \mathrm{CH}_{3}\right), 3.51-3.43\left(\mathrm{~m}, 4 \mathrm{H}, \mathrm{CH}_{2}\right), 3.59-3.52\left(\mathrm{~m}, 4 \mathrm{H}, \mathrm{CH}_{2}\right), 3.73-3.67\left(\mathrm{~m}, 4 \mathrm{H}_{1} \mathrm{CH}_{2}\right)$, 3.97-3.90 (m, 4H, CH $), 4.48-4.42\left(\mathrm{~m}, 4 \mathrm{H}, \mathrm{CH}_{2}\right)$ (Figure $\mathrm{S} 1$ in Supplementary Materials).

\subsubsection{Synthesis of the Polymers P1 and P2}

P1 and P2 were synthesized using a previously reported method [40] (shown in Scheme 1). The detailed procedure is as follows: a mixture of 2,7-dibromo-4,4,9,9-tetraoctyl-4,9-dihydro-s-indaceno[1-b:5,6-b']-dithiophene (0.200 g, $0.229 \mathrm{mmol})$, bis(trimethylstannyl) compound $(0.229 \mathrm{mmol}), \mathrm{Pd}_{2}(\mathrm{dba})_{3}(0.011 \mathrm{~g}, 0.011 \mathrm{mmol})$, and $\mathrm{P}(o-\mathrm{tol})_{3}(0.018 \mathrm{~g}$, $0.057 \mathrm{mmol})$ in anhydrous chlorobenzene $(5 \mathrm{~mL})$ with a nitrogen flow was sealed and stirred for $72 \mathrm{~h}$ at $110^{\circ} \mathrm{C}$. After the mixture was cooled to room temperature, the polymer was precipitated by the addition of excess methanol. The precipitate was sequentially washed with methanol, acetone, and deionized water. After drying under vacuum, the polymers were obtained as black powders.

P1: black powder, Yield $66 \%,{ }^{1} \mathrm{H}-\mathrm{NMR} \delta(\mathrm{ppm}): 1.35-0.49\left(\mathrm{~m}, 50 \mathrm{H}, \mathrm{CH}_{2}-\mathrm{CH}_{3}\right), 2.32-1.77(\mathrm{~m}, 8 \mathrm{H}$, $\left.\mathrm{CH}_{2}\right), 4.66-3.23\left(\mathrm{~m}, 20 \mathrm{H}, \mathrm{CH}_{2}\right), 7.44(\mathrm{~s}, 2 \mathrm{H}$, aromatic), 8.19 (s, 1H, thiophene), 8.57 (s, 1H, thiophene) (Figure S2).

P2: black powder, Yield $56 \%,{ }^{1} \mathrm{H}-\mathrm{NMR} \delta$ (ppm): $1.49-0.66\left(\mathrm{~m}, 74 \mathrm{H}, \mathrm{CH}_{2}-\mathrm{CH}_{3}\right), 2.23-1.89(\mathrm{~m}, 8 \mathrm{H}$, $\left.\mathrm{CH}_{2}\right), 4.21\left(\mathrm{~m}, 4 \mathrm{H}, \mathrm{CH}_{2}\right), 7.48-7.35(\mathrm{~m}, 2 \mathrm{H}$, aromatic), $8.42(\mathrm{~d}, 2 \mathrm{H}$, aromatic) (Figure $\mathrm{S} 3)$. 

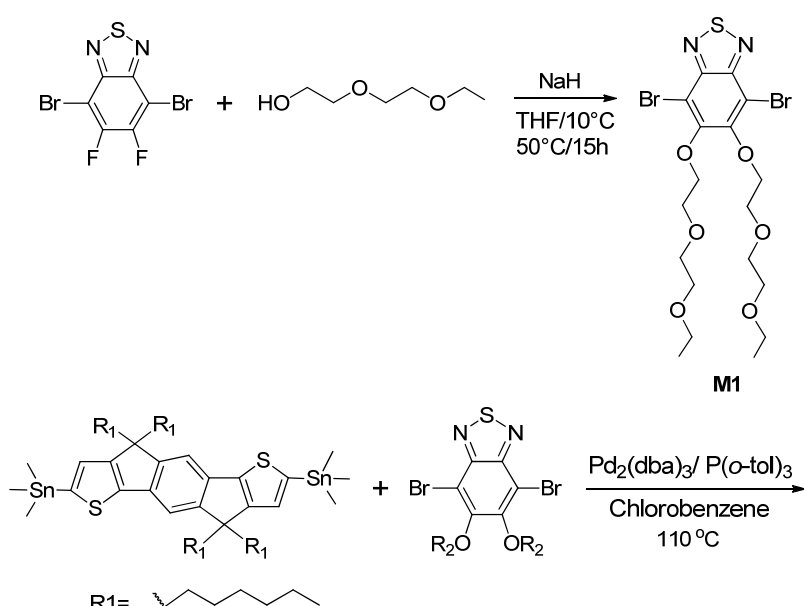

$\underset{\mathrm{Pd}_{2}(\mathrm{dba})_{3} / \mathrm{P}(\mathrm{o}-\mathrm{tol})_{3}}{\longrightarrow}$ $110^{\circ} \mathrm{C}$
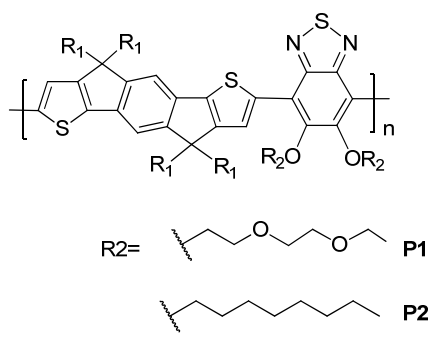

Scheme 1. Synthetic routes to the monomer M1 and copolymers P1 and P2.

\subsection{Preparation of the Thermoelectric Composites}

The $\mathrm{CP} / \mathrm{SWCNT}$ composite films were prepared by a drop-casting method following the preparation procedure shown in Scheme 2. Glass slides $(10 \mathrm{~mm} \times 10 \mathrm{~mm})$ were sequentially washed with acetone, ethanol, and deionized water in an ultrasonic bath for $30 \mathrm{~min}$. Then SWCNTs $(20 \mathrm{mg})$ were dispersed in anhydrous chlorobenzene $(20 \mathrm{~mL})$ to form a $1 \mathrm{mg} \mathrm{mL}^{-1}$ suspension; the polymer itself is also prepared as a $1 \mathrm{mg} \mathrm{mL}^{-1}$ solution. By mixing different amounts of polymer solutions and SWCNT suspensions we formed CPs/SWCNT composites with various amounts of SWCNTs. In a separate beaker, specific amounts of SWCNTs solution and polymer solutions are taken from the stock solutions by using pipettes and added to the beakers. The obtained mixtures were further sonicated for $3 \mathrm{~h}$ to produce homogeneous suspensions. Finally, the suspensions were drop-cast onto the surface of the glass slides to form the composite films after evaporating the solvents.

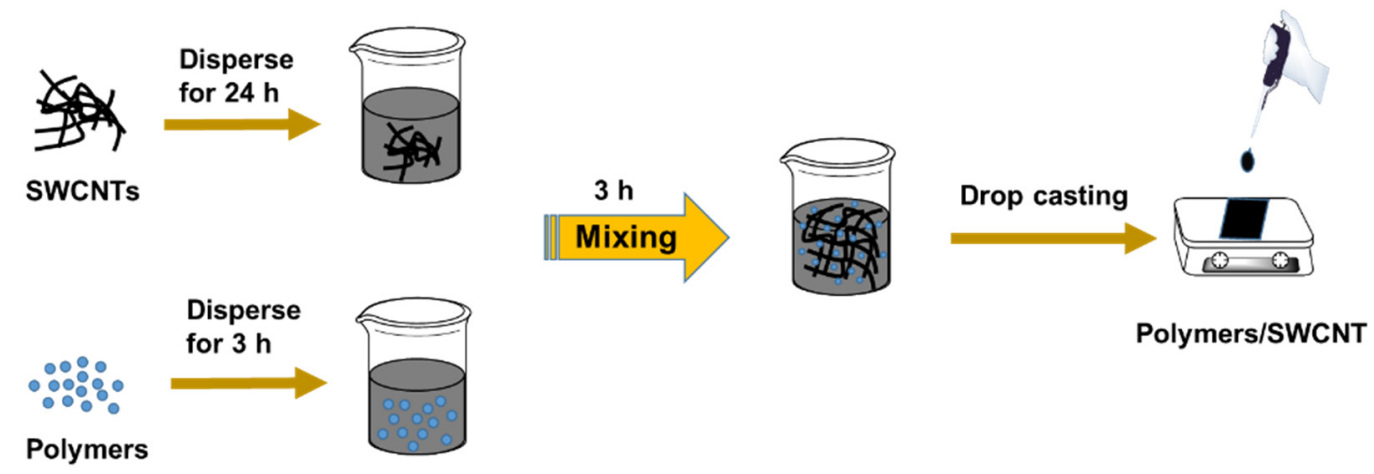

Scheme 2. Schematic illustration showing the preparation process for the conjugated polymers (CPs)/single wall carbon nanotubes (SWCNTs) composite films.

\section{Results and Discussion}

\subsection{Molecular Design, Synthesis, and Characterizations of the Copolymers}

The monomer M1 with attached polar oligoethylene glycol side chains was prepared by an in situ alkylation reaction of 2-(2-methoxyethoxy)ethanol with 4,7-dibromo-5,6-difluoro-2,1,3-benzothiadiazole. The polymers P1 and P2 were synthesized via Stille coupling in $80 \%$ yield by using $\operatorname{Pd}_{2}(\mathrm{dba})_{3}$ as a catalyst and toluene as a solvent. The detailed synthetic procedures are described in the Materials and Methods section. The chemical structures of 
the obtained polymers are characterized by ${ }^{1} \mathrm{H}-\mathrm{NMR}$ spectroscopy. By size exclusion chromatography (SEC) in tetrahydrofuran (THF), the number-average molecular weights of $\mathbf{P 1}$ and $\mathbf{P} \mathbf{2}$ are measured to be $11.6 \mathrm{kDa}$ (polydispersity index $(\mathrm{PDI})=1.8)$ and $20.6 \mathrm{kDa}(\mathrm{PDI}=2.0)$, respectively (Figures S4 and S5). The obtained polymers show good solubility in common organic solvents (e.g., chloroform, chlorobenzene, and $o$-dichlorobenzene). The thermal properties of the polymers were analyzed by thermogravimetric analysis (TGA) and differential scanning calorimetry (DSC) measurements. P1 and $\mathbf{P 2}$ showed the decomposition temperatures $\left(T_{\mathrm{d}}\right)$ with $5 \%$ weight loss at $361.5^{\circ} \mathrm{C}$ and $342.5^{\circ} \mathrm{C}$, respectively (Figure S6), indicating that both of $\mathbf{P 1}$ and $\mathbf{P 2}$ exhibited good thermal stability, and P1 with polar side chain showed better thermal stability than $\mathbf{P 2}$. The difference in the decomposition temperatures was likely due to the different side chains on the benzothiodazole units, where the polar side chains might have stronger bond energy and form stronger van der Waals forces, as it is reported that the length of a $\mathrm{CH}_{2}-\mathrm{O}$ bond $(1.42 \AA)$ is slightly shorter than that of the $\mathrm{CH}_{2}-\mathrm{CH}_{2}$ bond $(1.54 \AA)$ [41]. No melting transitions were observed for both polymers in the differential scanning calorimentry (DSC) measurements in the temperature range of $25-300{ }^{\circ} \mathrm{C}$, suggesting that $\mathbf{P 1}$ and $\mathbf{P 2}$ are both amorphous polymers (Figure S7).

Figure 1a shows the normalized UV-vis absorption spectra of $\mathbf{P 1}$ and $\mathbf{P} \mathbf{2}$ in film state, and the resulting optical properties are summarized in Table 1 . In the film state, two polymers exhibited identical absorption spectra with a sharp shoulder at around $670 \mathrm{~nm}$, which is attributed to the localized $\pi-\pi^{*}$ transitions due to the planar backbone of indacenodithiophene (IDT). The onsets of the absorption spectra for both $\mathbf{P 1}$ and $\mathbf{P 2}$ are $724 \mathrm{~nm}$ and $720 \mathrm{~nm}$, respectively, indicating both of them have similar optical bandgaps (P1: $1.71 \mathrm{eV}$; P2: $1.72 \mathrm{eV}$, respectively, Table 1).
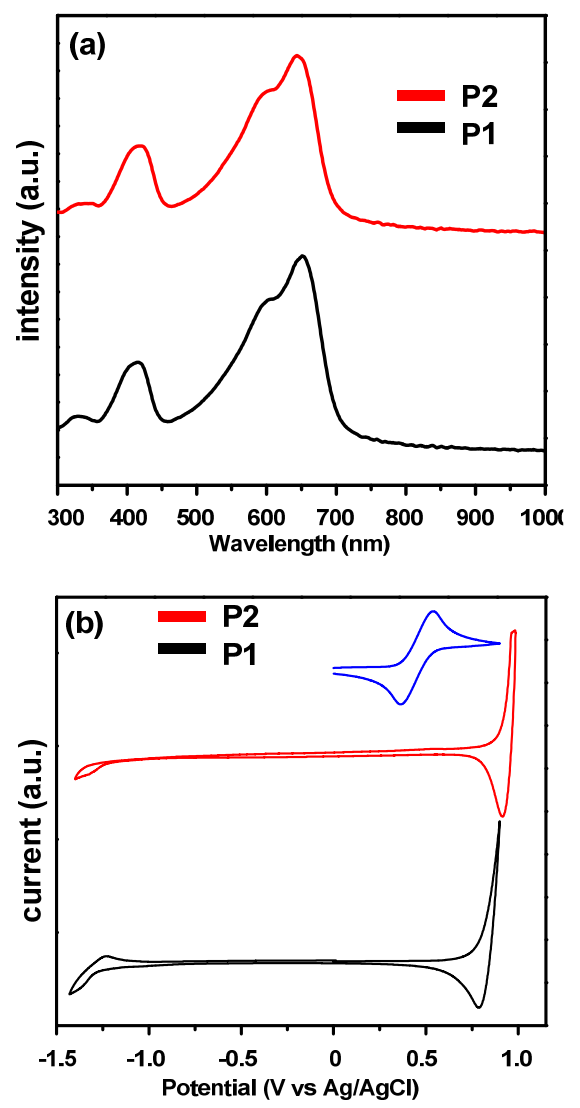

Figure 1. (a) Normalized UV-Vis absorption spectra of polymer films and (b) cyclic voltammograms (CV) of $\mathbf{P 1}$ and $\mathbf{P} 2$. 
Table 1. Summary of the Photophysical, Electrochemical, and Thermal Properties of P1 and P2.

\begin{tabular}{cccccccccc}
\hline Polym. & $\begin{array}{c}M_{\mathbf{n}}{ }^{\mathbf{a}} \\
\left(\mathbf{k g ~ m o l}^{-\mathbf{1}}\right)\end{array}$ & PDI & $\begin{array}{c}E^{\mathbf{o x}} \\
(\mathbf{e V})\end{array}$ & $\begin{array}{c}E^{\text {red }} \\
(\mathbf{e V})\end{array}$ & $\begin{array}{c}E_{\text {HOMO }} \mathbf{b} \\
(\mathbf{e V})\end{array}$ & $\begin{array}{c}E_{\text {LUMO }} \\
(\mathbf{e V})\end{array}$ & $\begin{array}{c}E \text { ec } \\
(\mathbf{e V})\end{array}$ & $\begin{array}{c}\lambda^{\text {onset }} \\
(\mathbf{n m})\end{array}$ & $\begin{array}{c}E^{\mathbf{o p}_{\mathbf{t g}}} \\
(\mathbf{e V})\end{array}$ \\
\hline P1 & 11.6 & 1.8 & 0.73 & -1.01 & -5.67 & -3.39 & 1.74 & 724 & 1.71 \\
P2 & 20.6 & 2.0 & 0.81 & -0.83 & -5.75 & -4.11 & 1.64 & 720 & 1.72 \\
\hline
\end{tabular}

${ }^{a}$ Number-average molecular weight $\left(M_{\mathrm{n}}\right)$ determined by SEC. ${ }^{\mathrm{b}}$ The HOMO energy levels of the polymers can be calculated from the $E_{\text {onset }}$ for oxidation $\left(E_{o x, \text { onset, polymer }}\right)$ using the equation: $E_{H O M O}=-E\left(E_{\text {ox, onset,polymer }}-E_{1 / 2, \text { ferrocene }}\right)$ $+(-5.39 \mathrm{ev})$. The LUMO energy levels are obtained using the following equation: $E_{L U M O}=-E\left(E_{r e, o n s e t, p o l y m e r}-\right.$ $\left.E_{1 / 2, \text { ferrocene }}\right)+(-5.39 \mathrm{ev})$. The band gap $E_{g}$ is calculated from the equalality: $E_{g}=E_{L U M O}-E_{H O M O}$.

The similar absorption spectra suggest that the electronic structures of the two polymers remain constant when the side-chains change. By cyclic voltammetry (CV) measurements (Figure 1b), the HOMO/LUMO frontier orbital energy levels were determined to be $-5.67 \mathrm{eV} /-3.39 \mathrm{eV}$ and $-5.75 \mathrm{eV} /-4.11 \mathrm{eV}$ for $\mathbf{P 1}$ and $\mathbf{P 2}$, respectively (Table 1). The lower oxidation potential of $\mathbf{P 1}$ compared to that of $\mathbf{P} 2$ should be attributed to the easy oxidation of the ethylene glycol ether side chain. The electronic bandgaps of $\mathbf{P} \mathbf{1}$ and $\mathbf{P 2}$ are determined to be $1.74 \mathrm{eV}$ and $1.64 \mathrm{eV}$, respectively, confirming the aforementioned optical properties of the polymers.

\subsection{Photophysical Properties of the $C P s / S W C N T$ Composite Films}

FT-IR spectra of P1/SWCNTs and P2/SWCNTs were recorded and are shown in Figure S10. In the case of $\mathbf{P} \mathbf{1} / \mathrm{SWCNTs}$ composites, the main absorption peaks of the polymers are described as follows: the absorption band of $560 \mathrm{~cm}^{-1}$ should be ascribed to the C-S bond of thiophene, the peak around $830 \mathrm{~cm}^{-1}$ is caused by the $\mathrm{C}-\mathrm{O}-\mathrm{C}$ bonds in the benzothiadiazole unit, the peak of $1255 \mathrm{~cm}^{-1}$ arises from the stretching vibration of unsaturated $\mathrm{C}-\mathrm{H}$ bonds and the peak of $1629 \mathrm{~cm}^{-1}$ is from the $\mathrm{C}=\mathrm{N}$ stretching vibration. P2/SWCNTs composite films exhibited similar absorption peaks as those of P1/SWCNTs composites, indicating that the electronic structures of polymers are not altered after adding different ratios of SWCNTs, namely, the polymers are quite stable in the composite films.

The UV-Vis absorption spectra were recorded to study the electronic band structures and interfacial interactions of P1/SWCNTs and P2/SWCNTs composites. The peak at around $270 \mathrm{~nm}$ should be assigned to SWCNTs, and its intensity was enhanced upon increasing the amounts of the SWCNTs (Figure 2a,b), accompanied by a shifting of the spectra by a few nanometers. The peaks at around $600 \mathrm{~nm}$ and $650 \mathrm{~nm}$ for P1/SWCNT composites shifted to small wavelengths as the amounts of SWCNTs increased, however, we noticed a small red shift of the peaks at around $600 \mathrm{~nm}$ and $650 \mathrm{~nm}$ to longer wavelengths for P2/SWCNTs, indicating that different packing styles existed in the P1/SWCNT and P2/SWCNT composites, and we speculate that the different packing features should be caused by the more intensified interfacial interactions of P1/SWCNTs than that of P2/SWCNTs, although the detailed packing features of the composites are still unclear at the current stage. 

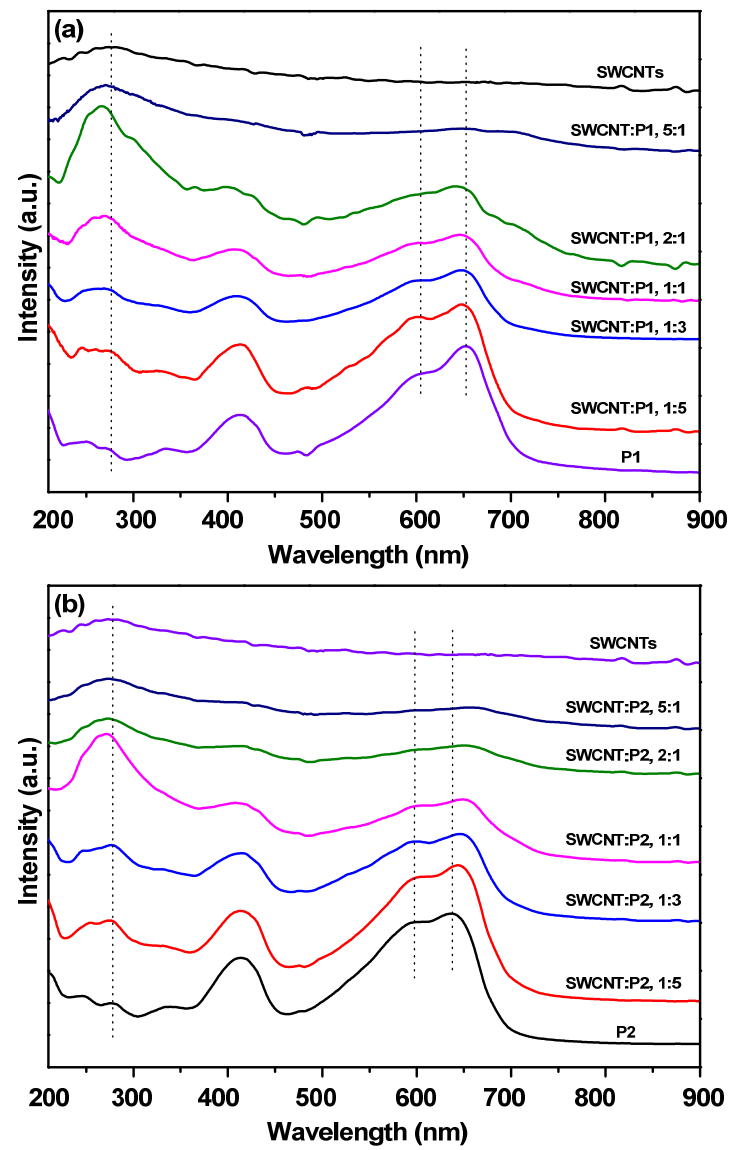

Figure 2. UV-Vis absorption spectra of (a) P1/SWCNTs and (b) P2/SWCNTs composite films with varying the amounts of SWCNTs.

\subsection{Surface Morphologies of the $C P_{S} / S W C N T$ Composite Films}

In order to investigate the effects of surface morphologies on the properties of the composites, the surface morphologies of $\mathrm{CPs} / \mathrm{SWCNT}$ were characterized by field scanning electron microscopy (FE-SEM) as shown in Figure 3 and Figure S9. It is clear that the SWCNTs bundles are distributed homogeneously on the composite films. Fibrillar structures are clearly observed from the images shown in Figure 3, which could be attributed to the successfully wrapping of polymers onto the SWCNTs surfaces through strong interfacial interactions between them. With increasing amounts of SWCNTs, the diameters of the bundled fibers becomes smaller, and the diameter of the pristine SWCNTs is the smallest one. Compared to P1/SWCNT composites, the surface morphology of P2/SWCNT as shown in Figure S9 exhibited small aggregates due to the relatively poor interactions between them. These results indicated that the existence of a polar side chain can be beneficial to form homogeneous composite films through the enhanced interfacial interactions between the polymer and SWCNTs. 


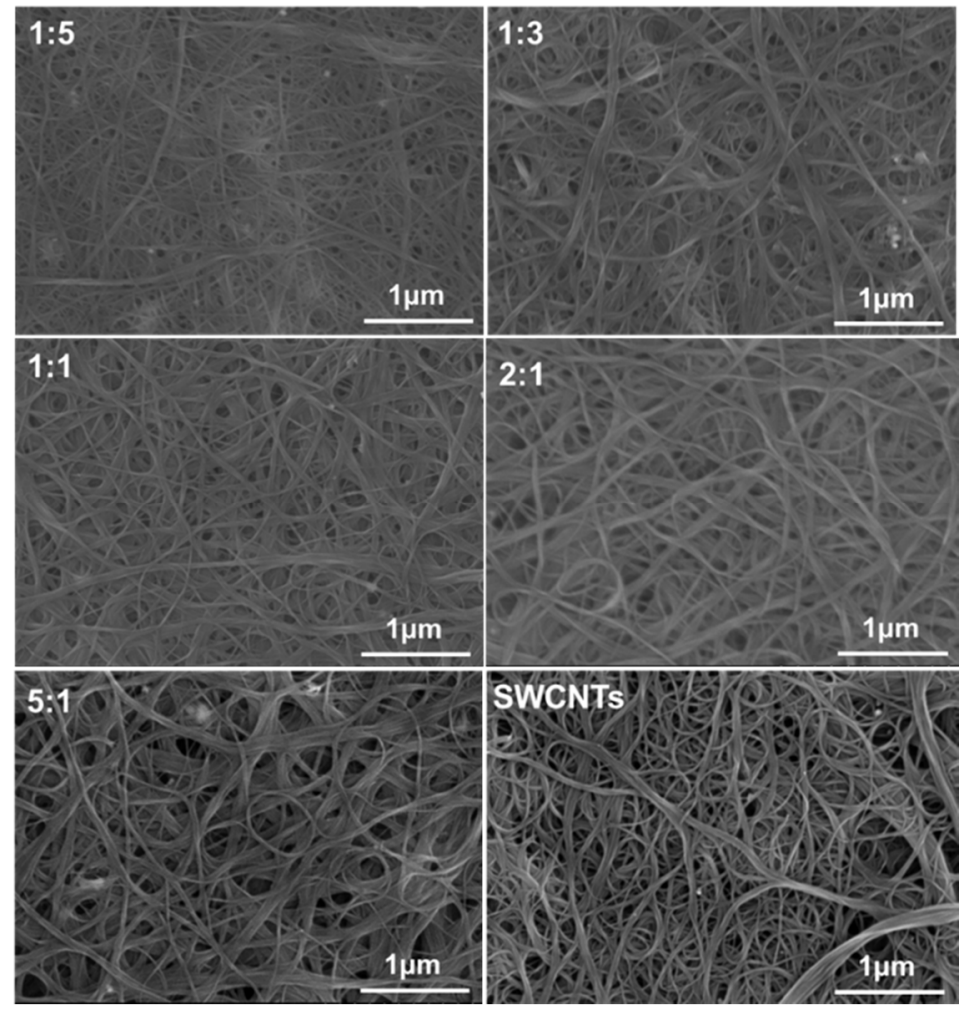

Figure 3. Scanning electron microscope (SEM) images of P1/SWCNTs composite films with different amounts of SWCNTs.

\subsection{Raman Spectroscopies of P1/SWCNTs and P2/SWCNTs Composites}

The Raman spectra of pristine polymers, SWCNTs, and the CPs/SWCNT composite films with different mass ratios of polymers to SWCNTs are presented in Figure 4 and Figure S8. The spectra of the pure SWCNTs showed characteristic peaks at 1562 and $1593 \mathrm{~cm}^{-1}$, respectively, where the peak at $1593 \mathrm{~cm}^{-1}$ could be assigned to the G band of SWCNTs that originates from the splitting of the $E_{2 \mathrm{~g}}$ stretching mode of graphite. Some important characteristic peaks were observed for the pristine P1 and $\mathbf{P 2}$ film. The peaks at around 1519 and $1610 \mathrm{~cm}^{-1}$ for $\mathbf{P 1}$ and 1510 and $1608 \mathrm{~cm}^{-1}$ for $\mathbf{P 2}$ should be attributed to the benzene ring stretching vibrations of the IDT and BT units. The peaks at around 1312 and $1421 \mathrm{~cm}^{-1}$ correspond to the $\mathrm{C}=\mathrm{C}$ symmetrical stretching mode of the thiophene segments for P1 and P2, respectively, and the peaks at 850 and $857 \mathrm{~cm}^{-1}$ could be attributed to the $C-C$ stretching vibrations of $\mathbf{P 1}$ and $\mathbf{P 2}$. In the case of composites films, the intensity of the characteristic peaks of the pristine $\mathbf{P 1}$ and $\mathbf{P 2}$ gradually decreased and eventually disappeared when the amount of SWCNTs was increased. We noticed that the G band peak of SWCNT showed shifts of approximately $2-5 \mathrm{~cm}^{-1}$ in the composite films of P1/SWCNTs, which is hardly observed in P2/SWCNTs composites, resulting from the strong $\pi-\pi$ interfacial interactions between the polymers and SWCNTs (Figure S8). 

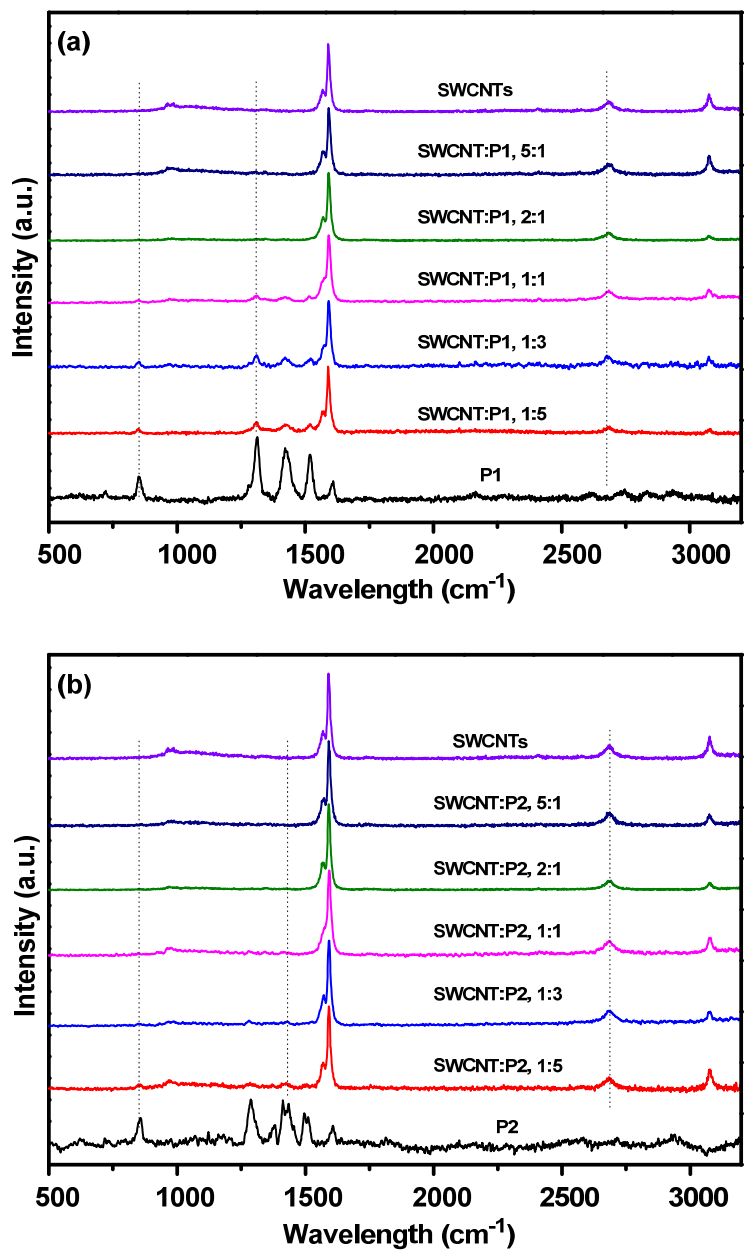

Figure 4. Raman spectra of (a) P1/SWCNTs composites and (b) P2/SWCNTs composites films with different amounts of SWCNTs.

In order to further investigate the interfacial interactions between polymers and the SWCNTs, grazing-incident X-ray diffraction (GI-XRD) was performed on the pristine P1, P2 and their SWCNTs composites films as shown in Figure 5 . There are no obvious $\pi-\pi$ stacking peaks for pristine $\mathbf{P 1}$ and P2 films, confirming the amorphous features of both polymers as confirmed by DSC. P1 showed a halo peak between $15^{\circ}$ to $30^{\circ}$, which is narrower than the halo peak of $\mathbf{P 2}$ (between $15^{\circ}$ to $40^{\circ}$ ), and in the meantime, there is a sharp peak at around $5.46^{\circ}$ for $\mathbf{P 1}$ and around $8.96^{\circ}$ for $\mathbf{P 2}$, indicating that the interpolymer chain distance of $\mathbf{P 1}$ is larger than that of $\mathbf{P 2}$. The larger interpolymer distance of P1 indicates that $\mathbf{P 1}$ tends to form looser packing than that of $\mathbf{P 2}$, which is beneficial to form homogenous surface morphologies with SWCNTs. In the XRD patterns of the P1/SWCNTs composite films, the sharp peak at around $5.46^{\circ}$ is significantly decreased as the amount of SWCNTs is increased, indicating that the polymers tend to bind with SWCNTs. The typical diffraction peak of pure SWCNT at $2 \theta=26.5^{\circ}$ moved to a slightly lower angle, and the intensity of the diffraction peak also decreased, which further proved the presence of strong $\pi-\pi$ interfacial interactions between P1 and SWCNTs, however, no obvious shifting of the peak was observed for P2/SWCNTs composite films. 

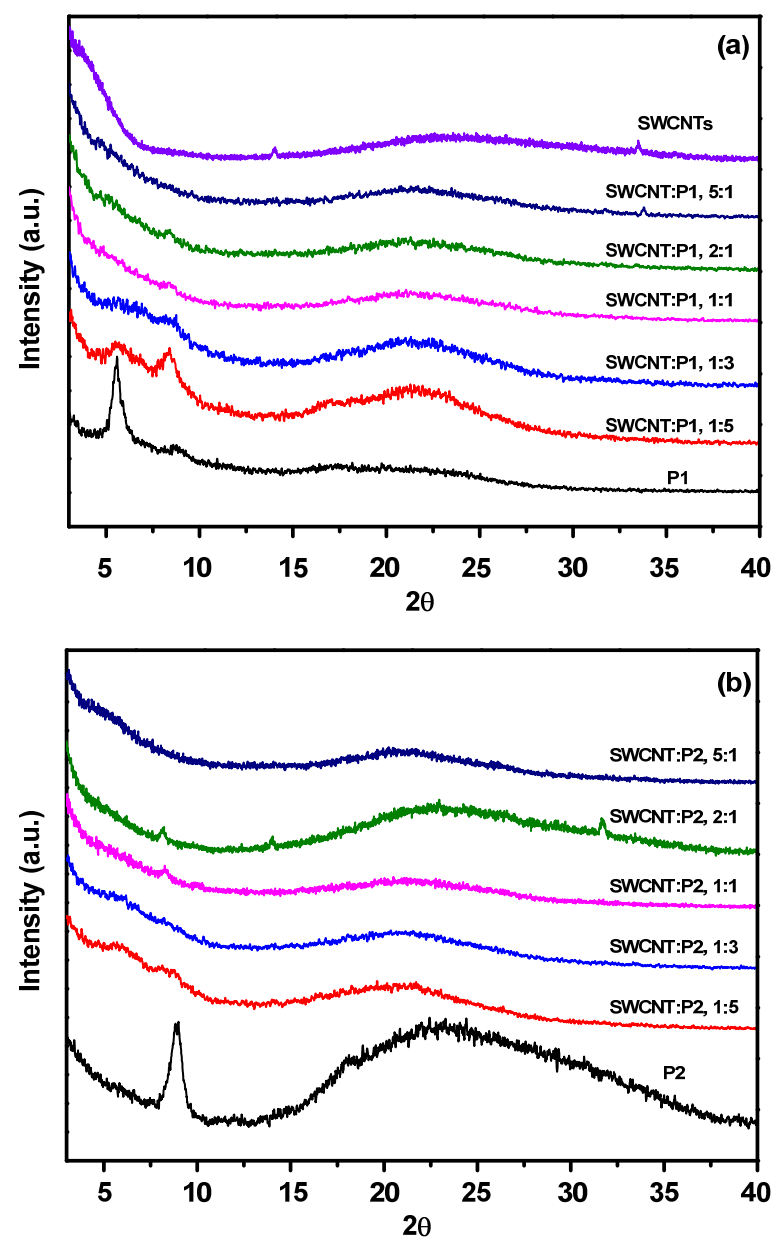

Figure 5. Grazing incidence X-ray diffraction (GI-XRD) spectra of the (a) pristine P1 and its SWCNT composites and (b) pristine $\mathbf{P} 2$ and its SWCNT composites.

\subsection{Thermoelectric Properties of P1/SWCNT and P2/SWCNT Composites}

The electrical conductivities and Seebeck coefficients are presented in Figure 6. The introduction of SWCNTs significantly improved the electrical conductivity of the composites. Both the P1/SWCNT and P2/SWCNT composites with 50\% SWCNTs exhibited the highest values of electrical conductivities, $3392.67 \mathrm{~S} \mathrm{~cm}^{-1}$ and $3283.09 \mathrm{~S} \mathrm{~cm}^{-1}$, respectively. These enhanced electrical conductivities could be generated from the formed homogeneous network structure of the composites films as shown in the SEM images (Figure 3). Further increasing the amount of SWCNTs was detrimental to the electrical conductivities of both of the P1/SWCNT and P2/SWCNT composites, probably due to the aggregation of SWCNTs that breaks the network structure of composites films. As shown in Figure 6, the maximum power factor value of $161.34 \mu \mathrm{W} \mathrm{m} \mathrm{m}^{-1} \mathrm{~K}^{-2}$ for P1/SWCNT (1:1, weight ratio) is higher than that of P2/SWCNT (139.06 $\left.\mu \mathrm{W} \mathrm{m}^{-1} \mathrm{~K}^{-2}\right)$ for the same ratio of the polymer and SWCNTs, due to the much larger Seebeck coefficient value of P1/SWCNTs composites. The maximum power factor value $(144.77 \mu \mathrm{W}$ $\mathrm{m}^{-1} \mathrm{~K}^{-2}$ ) for P2/SWCNT (2:1, weight ratio) is still lower than the maximum value of P1/SWCNTs. These results indicated that the incorporation of polar side chains to the indacenodithiophene-benzothiazole copolymers could improve the electrical conductivities as well as maintain the large Seebeck coefficient value of the polymers/SWCNTs composites, leading to enhanced thermoelectric performance. 
(a)

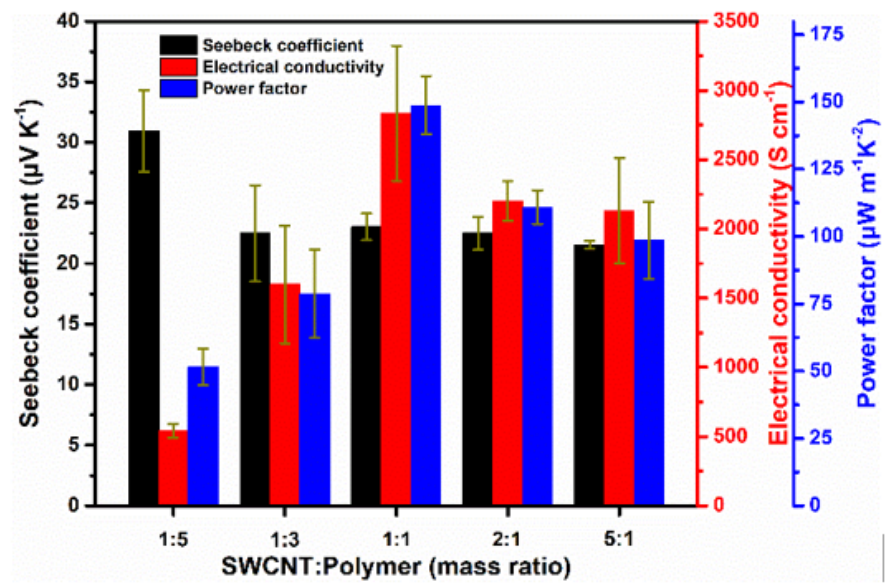

(b)

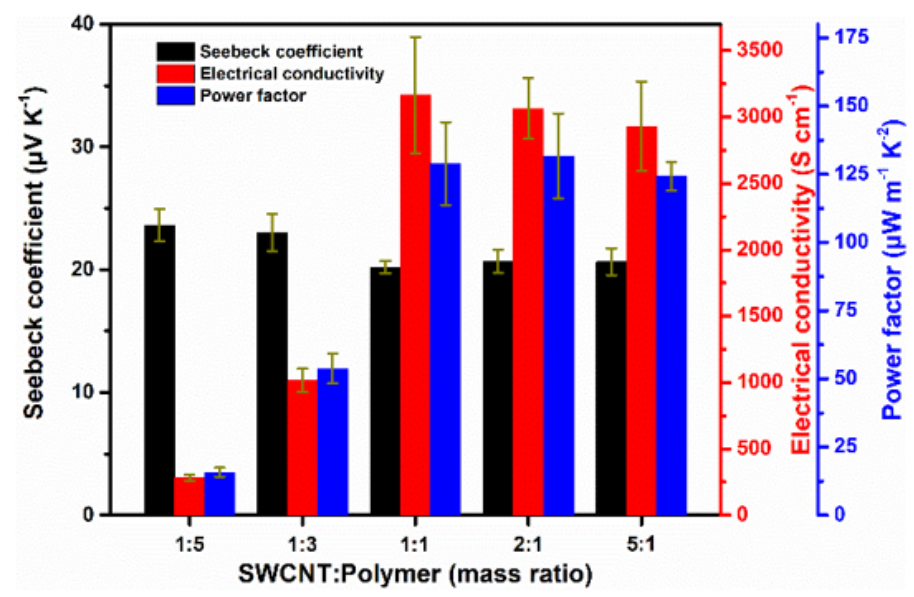

Figure 6. Electrical conductivities, Seebeck coefficients, and power factor values of P1/SWCNT (a) and P2/SWCNT composite films (b).

\section{Conclusions}

Two indacenodithiophene and benzothiazole alternating copolymers with triethylene glycol ether side chains (P1) and aliphatic side chains (P2) were synthesized and their corresponding composites with SWCNTs were prepared. Compared with the properties of P2 with an aliphatic side chain, P1 exhibited similar photophysical features, electronic properties and bandgaps. After forming composites with SWCNTs, P1 with a polar side chain possesses much stronger interactions with SWCNTs than those of P2, which has been evidenced by their UV-Vis, XRD, and Raman spectra characterizations. P1 with $50 \mathrm{wt} \%$ SWCNTs exhibited a PF value of $161.34 \mu \mathrm{W} \mathrm{m} \mathrm{m}^{-1} \mathrm{~K}^{-2}$ which is higher than the value of P2(139.06 $\left.\mu \mathrm{W} \mathrm{m}^{-1} \mathrm{~K}^{-2}\right)$ for the same amount of added SWCNTs. These results confirmed that the incorporation of polar side chains into the conjugated polymer backbone is an effective strategy to build thermoelectric conjugated polymer/SWCNT composites with high performance.

Supplementary Materials: The following are available online at http://www.mdpi.com/2073-4360/12/4/848/s1, Figure S1: ${ }^{1} \mathrm{H}$ NMR spectrum of M1, Figure S2: ${ }^{1} \mathrm{H}$ NMR spectrum of P1, Figure S3: ${ }^{1} \mathrm{H}$ NMR spectrum of P2, Figure S4: GPC curve of P1, Figure S5: GPC curve of P2, Figure S6: TGA curves of P1 and P2, Figure S7: DSC curves of P1 and P2, Figure S8: The G-band magnification of P1 films, SWCNTs, the P1/SWCNT composites films (a) and P2 films, SWCNTs, the P2/SWCNT composites films (b), Figure S9: SEM images of P2/ SWCNT composite films with different mass ratios of SWCNTs, Figure S10: FT-IR spectra of P1/SWCNT composite films with different mass ratios of SWCNTs (a) and P2/SWCNT composite films with different mass ratios of SWCNTs (b).

Author Contributions: Conceptualization, Z.C. and G.T.; Data curation, T.L.; Investigation, Z.C. and T.L.; Methodology, T.L.; Resources, C.P.; Supervision, C.P. and G.T.; Writing—original draft, Z.C.; Writing一review \& editing, C.P. All authors have read and agreed to the published version of the manuscript. 
Funding: This research was funded by National Natural Science Foundation of China (No. 21706030) and Science Foundation of Guangdong Province (No. 2018A0303130157).

Conflicts of Interest: The authors declare no conflict of interest.

\section{References}

1. Biswas, K.; He, J.; Blum, I.D.; Wu, C.-I.; Hogan, T.P.; Seidman, D.N.; Dravid, V.P.; Kanatzidis, M.K. High-Performance Bulk Thermoelectrics with All-scale Hierarchical Architectures. Nature 2012, 489, 414-418. [CrossRef]

2. Wang, H.; Yu, C. Organic Thermoelectrics: Materials Preparation, Performance Optimization, and Device Integration. Joule 2019, 3, 53. [CrossRef]

3. Liang, Z.; Chen, L.; Bazan, G.C. Organic and Hybrid Thermoelectrics. Adv. Electron. Mater. 2019, 5, 1900650. [CrossRef]

4. Poudel, B.; Hao, Q.; Ma, Y.; Lan, Y.; Minnich, A.; Yu, B.; Yan, X.; Wang, D.; Muto, A.; Vashaee, D.; et al. High-thermoelectric Performance of Nanostructured Bismuth Antimony Telluride Bulk Alloys. Science 2008, 320, 634-638. [CrossRef]

5. Wan, T.; Yin, X.; Pan, C.; Liu, D.; Zhou, X.; Gao, C.; Wong, W.-Y.; Wang, L. Boosting the Adhesivity of $\pi$-Conjugated Polymers by Embedding Platinum Acetylides towards High-Performance Thermoelectric Composites. Polymers 2019, 11, 593. [CrossRef]

6. Finefrock, S.W.; Zhang, G.; Bahk, J.-H.; Fang, H.; Yang, H.; Shakouri, A.; Wu, Y. Structure and Thermoelectric Properties of Spark Plasma Sintered Ultrathin PbTe Nanowires. Nano Lett. 2014, 14, 3466-3473. [CrossRef]

7. Kroon, R.; Mengistie, D.A.; Kiefer, D.; Hynynen, J.; Ryan, J.D.; Yu, L.; Müller, C. Thermoelectric Plastics: From Design to Synthesis, Processing and Structure-Property Relationships. Chem. Soc. Rev. 2016, 45, 6147-6164. [CrossRef]

8. Heeger, A.J. Semiconducting Polymers: The Third Generation. Chem. Soc. Rev. 2010, 39, $2354-2371$. [CrossRef]

9. Facchetti, A. p-conjugated Polymers for Organic Electronics and Photovoltaic Cell Applications. Chem. Mater. 2011, 23, 733-758. [CrossRef]

10. Lu, L.; Zheng, T.; Wu, Q.; Schneider, A.M.; Zhao, D.; Yu, L. Recent Advances in Bulk Heterojunction Polymer Solar Cells. Chem. Rev. 2014, 114, 8943-9021. [CrossRef]

11. Berggren, M.; Nilsson, D.; Robinson, N.D. Organic Materials for Printed Electronics. Nat. Mater. 2007, 6, 3-5. [CrossRef]

12. Zhao, X.; Zhan, X. Electron Transporting Semiconducting Polymers in Organic Electronics. Chem. Soc. Rev. 2011, 40, 3728-3743. [CrossRef]

13. Zhang, Q.; Sun, Y.; Xu, W.; Zhu, D. Organic Thermoelectric Materials: Emerging Green Energy Materials Converting Heat to Electricity Directly And Efficiently. Adv. Mater. 2014, 26, 6829-6851. [CrossRef]

14. Qu, S.; Ming, C.; Yao, Q.; Lu, W.; Zeng, K.; Shi, W.; Shi, X.; Uher, C.; Chen, L. Understanding the Intrinsic Carrier Transport in Highly Oriented Poly(3-hexylthiophene): Effect of Side Chain Regioregularity. Polymers 2018, 10, 815. [CrossRef]

15. Qu, S.; Yao, Q.; Yu, B.; Zeng, K.; Shi, W.; Chen, Y.; Chen, L. Optimizing the Thermoelectric Performance of Poly(3-hexylthiophene) through Molecular-Weight Engineering. Chem. Aisan J. 2018, 13, 3246-3253. [CrossRef]

16. Wu, S.; Wu, X.; Xing, W.; Sun, Y.; Zou, Y.; Xu, W.; Zhu, D. Backbone Structure Effect on the Thermoelectric Properties of IDT-Based P-type Conjugated Polymers. Macromol. Rapid Commun. 2020, 41, 1900322. [CrossRef]

17. Jiang, F.X.; Xu, J.K.; Lu, B.Y.; Xie, Y.; Huang, R.J.; Lai, L.F. Thermoelectric performance of poly(3,4-ethylenedioxythiophene): Poly (styrene sulfonate). Chin. Phys. Lett. 2008, 25, 2202.

18. Kim, G.H.; Shao, L.; Zhang, K.; Pipe, K.P. Engineered Doping of Organic Semiconductors for Enhanced Thermoelectric Efficiency. Nat. Mater. 2013, 12, 719-723. [CrossRef]

19. McGrail, B.T.; Sehirlioglu, A.; Pentzer, E. Polymer Composites for Thermoelectric Applications. Angew. Chem. Int. Ed. 2015, 54, 1710-1723. [CrossRef] 
20. Wu, G.; Zhang, Z.-G.; Li, Y.; Gao, C.; Wang, X.; Chen, G. Exploring High-Performance n-Type Thermoelectric Composites Using Amino-Substituted Rylene Dimides and Carbon Nanotubes. ACS Nano 2017, 11, 5746-5752. [CrossRef]

21. Wang, L.; Pan, C.; Chen, Z.; Zhou, W.; Gao, C.; Wang, L. Enhanced Thermoelectric Performance of Conjugated Polymer/Single-Walled Carbon Nanotube Composites with Strong Stacking. ACS Appl. Energy Mater. 2018, 1, 5075-5082. [CrossRef]

22. Yan, X.; Xiong, M.; Li, J.-T.; Zhang, S.; Ahmad, Z.; Lu, Y.; Wang, Z.-Y.; Yao, Z.-F.; Wang, J.-Y.; Gu, X.; et al. Pyrazine-Flanked Diketopyrrolopyrrole (DPP): A New Polymer Building Block for High-Performance n-Type Organic Thermoelectrics. J. Am. Chem. Soc. 2019, 141, 20215-20221. [CrossRef]

23. Pan, C.; Wang, L.; Liu, T.; Zhou, X.; Wan, T.; Wang, S.; Chen, Z.; Gao, C.; Wang, L. Polar Side Chain Effects on the Thermoelectric Properties of Benzo[1,2-b:4,5-b']Dithiophene-Based Conjugated Polymers. Macromol. Rapid Commun. 2019, 40, 1900082. [CrossRef]

24. Kiefer, D.; Giovannitti, A.; Sun, H.; Biskup, T.; Hofmann, A.; Koopmans, M.; Cendra, C.; Weber, S.; Koster, L.J.A.; Olsson, E.; et al. Enhanced n-Doping Efficiency of a Naphthalenediimide-Based Copolymer through Polar Side Chains for Organic Thermolectrics. ACS Energy Lett. 2018, 3, 278-285. [CrossRef]

25. Xu, S.; Hong, M.; Shi, X.L.; Wang, Y.; Ge, L.; Bai, Y.; Wang, L.; Dargusch, M.; Zou, J.; Chen, Z.G. High-Performance PEDOT:PSS Flexible Thermoelectric Materials and Their Devices. Chem. Mater. 2019, 31, 5238-5244. [CrossRef]

26. Liang, L.; Chen, G.; Guo, C.-Y. Polypyrrole Nanostructures and Their Thermoelectric Performance. Mater. Chem. Front. 2017, 1, 380-386. [CrossRef]

27. Wu, G.; Xue, Y.; Wang, L.; Wang, X.; Chen, G. Flexible Gel-state Thermoelectrochemical Materials with Excellent Mechanical and Thermoelectric Performances based on Incorporating Sn2+/Sn4+ Electrolyte into Polymer/Carbon Nanotube Composites. J. Mater. Chem. A 2018, 6, 3376-3380. [CrossRef]

28. Peng, X.X.; Qiao, X.; Luo, S.; Yao, J.A.; Zhang, Y.F.; Du, F.P. Modulating Carrier Type for Enhanced Thermoelectric Performance of Single-Walled Carbon Nanotubes/Polyethyleneimine Composites. Polymers 2019, 11, 1295. [CrossRef]

29. Niu, R.; Pan, C.; Chen, Z.; Wang, L.; Wang, L. Enhanced Thermoelectric Performance from Self-assembled Alkyl Chain-linked Naphthalenediimide/Single Walled Carbon Nanotubes Composites. Chem. Eng. J. 2020, 381, 122650. [CrossRef]

30. Xiao, C.; Xue, Y.; Liu, M.; Liu, X.; Wu, X.; Wang, Z.; Xu, Y.; Chen, G. Polymer Composites with Lychee-like Core Covered by Segregated Conducting and Flexible Networks: Unique morphology, High flexibility, Stretchability and Thermoelectric Performance. Compos. Sci. Technol. 2018, 161, 16-21. [CrossRef]

31. Wang, X.; Wang, H.; Liu, B. Carbon-Based Organic Thermoelectric Materials for Energy Harvesting. Polymers 2018, 10, 1196. [CrossRef] [PubMed]

32. Wang, H.; Hsu, H.; Yi, S.; Kim, S.; Choi, K.; Yang, G.; Yu, C. Thermally Driven Large N-type Voltage Responses from Hybrids of Carbon Nanotubes and Poly(3,4-ethylenedioxythiophene) with Tetrakis(dimethylamino)ethylene. Adv. Mater. 2015, 27, 6855-6861. [CrossRef]

33. Du, Y.; Niu, H.; Li, J.; Dou, Y.; Shen, S.Z.; Jia, R.; Xu, J. Morphologies Tuning of Polypyrrole and Thermoelectric Properties of Polypyrrole Nanowire/Graphene Composites. Polymers 2018, 10, 1143. [CrossRef] [PubMed]

34. Yao, Q.; Wang, Q.; Wang, L.; Chen, L. Abnormally Enhanced Thermoelectric Transport Properties of SWNT/PANI Hybrid Films by the Strengthened PANI Molecular Ordering. Energy Environ. Sci. 2014, 7, 3801-3807. [CrossRef]

35. Liu, F.; Zhou, X.; Pan, C.; Wang, L. A facile Method to Intimately Contacted Nanocomposites as Thermoelectric Materials: Noncovalent Heterojunctions. J. Power Source 2019, 412, 153-159. [CrossRef]

36. Chen, Y.; He, M.; Liu, B.; Bazan, G.C.; Zhou, J.; Liang, Z. Bendable n-Type Metallic Nanocomposites with Large Thermoelectric Power Factor. Adv. Mater. 2016, 29, 1604752. [CrossRef]

37. Mai, C.K.; Russ, B.; Fronk, S.L.; Hu, N.; Chan-Park, M.B.; Urban, J.J.; Segalman, R.A.; Chabinyc, M.L.; Bazan, G.C. Varying the Ionic Functionalities of Conjugated Polyelectrolytes Leads to Both P-and N-type Carbon Nanotube Composites for Flexible Thermoelectrics. Energy Environ. Sci. 2015, 8, 2341-2346. [CrossRef]

38. Bounioux, C.; Díaz-Chao, P.; Campoy-Quiles, M.; Martín-González, M.S.; Goñi, A.R.; Yerushalmi-Rozen, R.; Müller, C. Thermoelectric Composites of Poly(3-hexylthiophene) and Carbon Nanotubes with a Large Power Factor. Energy Environ. Sci. 2013, 6, 918-925. [CrossRef] 
39. Rablen, P.R.; McLarney, B.D.; Karlow, B.J.; Schneider, J.E. How Alkyl Halide Structure Affects E2 and $\mathrm{S}_{\mathrm{N}} 2$ Reaction Barriers: E2 Reactions Are as Sensitive as $\mathrm{S}_{\mathrm{N}} 2$ Reactions. J. Am. Chem. Soc. 2014, 79, 867-879. [CrossRef]

40. Zhang, W.; Smith, J.; Watkins, S.E.; Gysel, R.; MvGehee, M.; Salleo, A.; Kirkpatrick, J.; Ashraf, S.; Anthopoulos, T.; Heeney, M.; et al. Indacenodithiophene Semiconducting Polymers for High-Performance, Air-Stable Transistors. J. Am. Chem. Soc. 2010, 132, 11437-11439. [CrossRef]

41. Chen, L.; Liu, W.; Yan, Y.; Su, X.; Xiao, S.; Lu, X.; Uher, C.; Tang, X. Fine-Tuning the Solid-State Ordering and Thermoelectric Performance of Regioregular P3HT Analogues by Sequential Oxygen-Substitution of Carbon Atoms Along the Alkyl Side -Chains. J. Mater. Chem. C 2019, 7, 2333-2344. [CrossRef]

C 2020 by the authors. Licensee MDPI, Basel, Switzerland. This article is an open access article distributed under the terms and conditions of the Creative Commons Attribution (CC BY) license (http://creativecommons.org/licenses/by/4.0/). 